\title{
Selection of black spruce progenies for the genetic improvement of height growth
}

\section{E. K. MORGENSTERN}

Canadian Forestry Service

Petawawa Forest Experiment Station

Chalk River, Ont.

Selection and breeding of rapidly growing trees is one way to improve growth in species that are established artificially. Unlike characters of the stem and crown, characters of growth are usually inherited to a lesser degree and rapidly growing genotypes are not easily identified. Studies of the genetic variation in black spruce (Picea mariana Mill. B.S.P.) at Petawawa Forest Experiment Station indicated that in a nursery experiment only $18 \%$ of the variation in total height was genetically controlled (Morgenstern 1973). This was no surprise in view of the low heritability of height growth reported from other species. While there is no doubt that selection for height growth is possible, it is clear that this requires very special procedures. The problem of developing and applying such procedures should interest management foresters and geneticists alike and is discussed here.

\section{Rank of trees and their progenies} in different environments

The concept of heritability implies that the total variation in a population of trees consists of two parts: that determined by the environment and that determined by genetic factors. Experiments with clones or progenies of individual trees are required to separate the influence of the two parts and calculate their percentage contribution.

In such experiments a given degree of control of a certain character by genetic factors (i.e. the heritability of this character) is manifested by the consistency of response in a number of environments. Characters that are strongly inherited will not change much in different environments while characters with weak inheritance will change more. When the progenies are ranked, say for the character height growth in two environments, the difference in rank may be used to compute Spearman's rank correlation coefficient (Steel and Torrie 1960). A very strong rank correlation would be expected for a character with high heritability and a weak correlation for another character with low heritability. Therefore the rank correlation can be used to express the meaning of a known heritability. Progeny rank is also important because it is used in selection.

In September 1963, four 30- to 50-year-old black spruce stands at Petawawa were located and five individual trees in each of them designated for seed collection and determination of height and age (Morgenstern 1969). No effort was made to select superior trees, but there was a tendency to prefer dominant trees because of their more prolific cone production. Seedlings were then raised from these female parents and planted into 2 experiments: $1 /$ a nursery experiment with 10-tree plots and 4 replications each on a moist and a dry site, where measurements of total height were made following the completion of the fourth growing season; and $2 /$ using the same nursery trees, a field experiment on a fresh site with 5-tree plots and 5 replications which was measured after the completion of the ninth season. The data from the nursery experiment have been previously used to obtain the heritability estimate referred to above (Morgenstern 1973). For the purposes of this study, measurement results were then available from 5 "environments": $1 /$ the growth of each female parent in its native environment; 2-4/ the growth of progenies on the dry nursery site, moist nursery site, as well as all replications on both sites in the nursery together, here termed the "combined site"; and 5/ the growth of the progenies on the fresh field site.

Progeny growth was analysed by variance and the significance evaluated using a multiple-range test (Duncan 1955). Differences significant at the $5 \%$ level of probability were found in both the nursery and field experiment. However, the principal aim of this analysis was to obtain rank correlations between parental growth and progeny growth in the different environments and thereby seek guidance on how to select. Towards this end, the rank of the female parent trees based on mean annual increment in the 4 stands and of the progenies on the 4 sites is given in Table 1 and the rank correlation coefficients in Table 2 .

Of the 10 possible rank correlation coefficients, only 3 were significant (Table 2). None of the progeny-parent correlations were significant: the simple assessment of mother tree growth made here (which did not take account of competition or microsite differences within a stand) was not a useful guide to growth of the progeny in the nursery (age 4) and field (age 9). On the other hand, progeny ranks on the moist site and dry site were correlated with ranks on the combined site - which is not surprising since the combined site means were merely obtained by pooling the data from the 4 replications each on the moist and dry site. However, of the rank comparisons between the nursery sites (age 4) and field (age 9), only the combined site was correlated with the field. Regarding the possibility of selection in these different environments when heritability is low, it is concluded that: 
selection in natural stands is ineffective if based on such simple comparisons of growth as applied here; a more effective method could be selection on the basis of the general regression of height over age in the same stand, whereby the selected tree should be one or two standard deviations above the mean at a given age, or by some other similar method (van Buijtenen 1969, Morgenstern et al. 1974); however, all of these methods will prove to be time consuming and costly;

- selection based upon experiments, where spacing and age are controlled, and populations are replicated over a range of environments, is more promising.

\section{Selection of the best progenies}

When selection is carried out, a significant rank correlation leads one to expect that some of the best progenies selected in different environments will be the same. However, if only a small percentage is selected, a very high rank correlation is needed before some of the same progenies will be selected in different environments. This is seen in Table 3. For example, if the tallest 5 progenies ( $25 \%$ of the population) are selected on the moist and combined nursery site, the order is number $8,4,6,11,14$ on the moist site and $8,11,4,10,20$ on the combined site. Therefore, only 3 out of 5 progenies, namely 8,4 and 11 , would be selected on both sites.

For selection at the same age, i.e. in the nursery, the results are summarized below:

\begin{tabular}{ccc}
\hline $\begin{array}{c}\text { Percent } \\
\text { selected }\end{array}$ & $\begin{array}{c}\text { Sites } \\
\text { compared }\end{array}$ & $\begin{array}{c}\text { Number of same } \\
\text { progenies }\end{array}$ \\
25 & Moist and combined & 3 \\
25 & Dry and combined & 4 \\
50 & Moist and combined & 8 \\
\hline
\end{tabular}

For selection at different ages, i.e. in the nursery at age 4 and field at age 9 , the corresponding figures are:

\begin{tabular}{ccc}
\hline $\begin{array}{c}\text { Percent } \\
\text { selected }\end{array}$ & $\begin{array}{c}\text { Sites } \\
\text { compared }\end{array}$ & $\begin{array}{c}\text { Number of same } \\
\text { progenies }\end{array}$ \\
25 & Combined \& Field & 1 \\
50 & Combined \& Field & 8 \\
\hline
\end{tabular}

Thus, if only the first 5 or fewer of the 20 progenies are selected, i.e. $25 \%$ or less of the population, only a fraction of the progenies selected in different environments is the same. If the first 10 are selected $(50 \%)$, there is more overlap but a final selection of a percentage as large as this would be unusual since it would lead to a very small improvement. Secondly, as expected, the selection at different ages again decreases the likelihood of selecting identical progenies, for only one of the first 5 progenies selected on the combined site would also have been selected in the field. Therefore, early selection does not appear to offer an easy solution to the selection problem in this
TABLE 1. The rank order of 20 female parent trees in their natural stands ${ }^{\mathrm{a}}$ based on mean annual increment and of their progenies on three nursery sites (age 4 years) and on a field site (age 9) based on total height

\begin{tabular}{|c|c|c|c|c|c|}
\hline \multirow{3}{*}{$\begin{array}{c}\text { Parent } \\
\text { no. }\end{array}$} & \multicolumn{5}{|c|}{ RANK ORDER } \\
\hline & \multirow[b]{2}{*}{ Natural stand } & \multicolumn{3}{|c|}{ Nursery site } & \multirow[b]{2}{*}{ Field site } \\
\hline & & Dry & Moist & Combined & \\
\hline 1 & 8 & 10 & 19 & 16 & 14 \\
\hline 2 & 14 & 9 & 15 & 12 & 12 \\
\hline 3 & 3 & 19 & 11 & 18 & 15 \\
\hline 4 & 13 & 8 & 2 & 3 & 6 \\
\hline 5 & 11 & 7 & 17 & 13 & 19 \\
\hline 6 & 18 & 12 & 3 & 6 & 10 \\
\hline 7 & 6 & 6 & 16 & 11 & 4 \\
\hline 8 & 4 & 1 & 1 & 1 & 11 \\
\hline 9 & 10 & 18 & 18 & 20 & 17 \\
\hline 10 & 7 & 2 & 14 & 4 & 5 \\
\hline 11 & 9 & $\overline{4}$ & 4 & 2 & 7 \\
\hline 12 & 15 & 14 & 20 & 19 & 20 \\
\hline 13 & 5 & 20 & 6 & 17 & 18 \\
\hline 14 & 17 & 16 & 5 & 8 & 1 \\
\hline 15 & 12 & 5 & 12 & 7 & 2 \\
\hline 16 & 16 & 15 & 7 & 10 & 13 \\
\hline 17 & 19 & 13 & 10 & 14 & 16 \\
\hline 18 & 2 & 11 & 9 & 9 & 8 \\
\hline 19 & 1 & 17 & 8 & 15 & 3 \\
\hline 20 & 20 & 3 & 13 & 5 & 9 \\
\hline $\begin{array}{l}\text { Range } \\
\mathrm{cm}\end{array}$ & $21-41 / \mathrm{yr}$ & $55-80$ & $65-85$ & $64-82$ & $170-216$ \\
\hline $\begin{array}{l}\text { Mean } \\
\mathrm{cm}\end{array}$ & $32 / \mathrm{yr}$ & 67 & 75 & 71 & 193 \\
\hline
\end{tabular}

"For the natural stand, ranking is based upon the percentage of growth of each parent in relation to stand mean growth.

TABLE 2. Rank correlation coefficients ${ }^{\mathrm{a}}$ of parental and progeny height growth in five environments

Environment

1/Female parents in natural stands

2/Progeny, moist

nursery site

3/Progeny, dry

nursery site

4/Progeny, dry

\& moist combined

5/Progeny, field site

$$
\begin{array}{rcccr}
\mathbf{1} & \mathbf{2} & \mathbf{3} & \mathbf{4} & \mathbf{5} \\
- & +3.0 & -.07 & -.15 & +.10 \\
& - & +.02 & +.61^{* *} & +.38 \\
& & - & +.76^{* *} & +.37
\end{array}
$$

"Significance level: **, $1 \%$.

TABLE 3. The best five and best 10 progenies (progeny numbers in italics) in each environment and their height

Total height in $\mathrm{cm}^{\mathrm{a}}$

\begin{tabular}{rrrrrrrr}
\multicolumn{2}{c}{ Dry } & & Moist & $\begin{array}{c}\text { Dry \& moist } \\
\text { combined }\end{array}$ & \multicolumn{2}{c}{ Field } \\
8 & 80 & 8 & 85 & 8 & 82 & 14 & 216 \\
10 & 76 & 4 & 82 & 11 & 77 & 15 & 211 \\
20 & 74 & 6 & 82 & 4 & 76 & 19 & 204 \\
11 & 73 & 11 & 81 & 10 & 74 & 7 & 202 \\
15 & 72 & 14 & 80 & 20 & 74 & 10 & 200 \\
7 & 70 & 13 & 78 & 6 & 73 & 4 & 199 \\
5 & 70 & 16 & 78 & 15 & 73 & 11 & 197 \\
4 & 69 & 19 & 77 & 14 & 72 & 18 & 196 \\
2 & 68 & 18 & 77 & 18 & 71 & 20 & 195 \\
1 & 68 & 17 & 76 & 16 & 71 & 6 & 195
\end{tabular}

aRounded off to the nearest $\mathrm{cm}$. 
species. Its value may lie primarily in the possibility of reducing population size for subsequent planting into long-term field tests.

That the results of this study are not unusual has been shown by studies in other species. For example, a study by Snyder (1969) conducted with longleaf pine (Pinus palustris Mill.) in Mississippi indicated that comparison trees proved ineffective as an aid to phenotypic selection of parent trees in the forest in spite of little competition in the open-grown stands. Mean annual height growth of parents was the principal variable involved in realizing a gain for height of $12 \%$ through phenotypic selection in the forest. However, gain from selection in progeny tests was $35 \%$, i.e. almost 3 times larger. Here again selection in replicated tests has been much more effective than selection in the wild.
Literature cited

DUNCAN, D.B. 1955. Multiple range and multiple $F$ tests Biometrics 11: 1-42.

MORGENSTERN, E.K. 1969. Genetic variation in seedlings of Picea mariana (Mill.) BSP. Silvae Genet. 18: 151-167.

MORGENSTERN, E.K. 1973. Heritability and genetic gain for height growth in a nursery experiment with black spruce. Can. Forest. Serv. Inform. Rep. PS-X-44. 10 p.

MORGENSTERN, E.K., M.J. HOLST, A.H. TEICH, and C.W. YEATMAN. 1974. Plus-tree selection: review and outlook. Can. Forest. Serv. Pub. (In press).

SNYDER, E.B. 1969. Parental selection versus half-sib family selection of longleaf pine, p. 84-86. In Proc. Tenth South. Conf. Forest Tree Improvement.

STEEL, R.G.D., and J.H. TORRIE. 1960. Principles and procedures of statistics. McGraw-Hill, New York. 481 p.

VAN BUIJTENEN, J.P. 1969. Progress and problems in forest tree selection, p. 17-26. In Proc. Tenth South. Conf. Forest Tree Improvement.

\section{IT WON'T YELL "CHAINS!"}

But you don't have to pay it either. When Pete First saw our silent friend, he smiled and exclaimed, "What would I do with a red briefcase in the bush???

Now Pete is using this "Red Briefcase" (we call it the TOPOFIL) to lay out Cutblocks, Stream or Lakeside Reserves, Road Traverses, etc. He does it fast and at $0.2 \%$ error, IT'S ACCURATE!

When Pete has to dash out to the field, there is no looking around for someone to tag along, because our TOPOFIL is already in the truck waiting!

Some call it "The Mechanical Compassman", but Pete calls it a "good deal". He can measure up to 15 miles a day, using the TOPOFIL and a ski-doo!

It will give you such satisfaction that you will wonder why this Two-
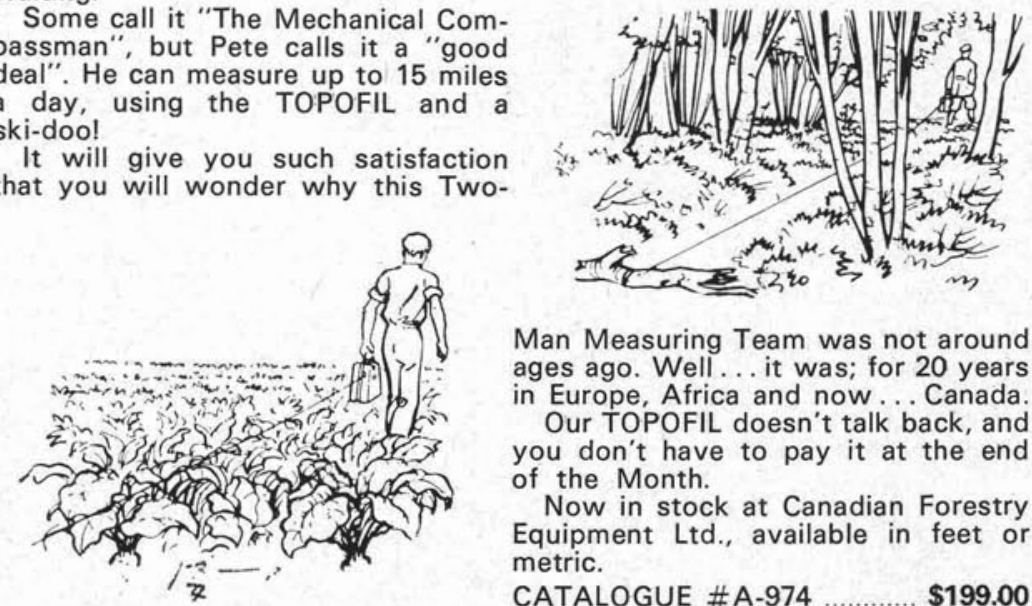

Man Measuring Team was not around ages ago. Well... it was; for 20 years in Europe, Africa and now... Canada.

Our TOPOFIL doesn't talk back, and you don't have to pay it at the end of the Month.

Now in stock at Canadian Forestry Equipment Ltd., available in feet or metric.

CATALOGUE \#A-974 ............. \$199.00

\section{CANADIAN FORESTRY EQUIPMENT LTD.}

5489 ROYALMOUNT AVE., MONTREAL, P. Q.
11004 - 166 A Street, EDMONTON, ALBERTA.
SOUEEZE A NICE LITTLE NUMBER

or letter and other marks in either print or script form.

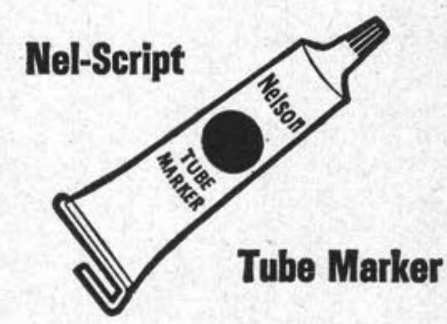

Paste paint in a flexible plastic tube that is squeezed to apply heavy bead or ribbon marks to both rough and smooth surfaces. The nozzle is easily shaped by cutting, making it possible to produce very small, inconspicuous numbers, letters or symbols. Hand pressure on the tube easily forces paint into the deepest crevices of extremely rough bark. When applied properly the paint marks will remain visible for many years. Turn key keeps paint at top of tube. Available in three colors - white, blue and green.

\section{NELSON}

Canadian Distributors: CANADIAN WARREN PINK LTD., St. Catharines, Ont. - Vancouver, B.C. GEORGE H. HEWITT CO. LTD., Vancouver, B.C. 